\title{
Copper-induced increased expression of genes involved in photosynthesis, carotenoid synthesis and $C$ assimilation in the marine alga Ulva compressa
}

Felipe E. Rodríguez ${ }^{1}$, Daniel Laporte ${ }^{1 *}$, Alberto González ${ }^{1}$, Katterinne N. Mendez², Eduardo Castro-Nallar², Claudio Meneses ${ }^{3,4}$, Juan Pablo Huidobro-Toro ${ }^{1,5}$ and Alejandra Moenne ${ }^{1 *}$ (D)

\begin{abstract}
Background: The marine alga Ulva compressa is the dominant species in coastal areas receiving effluents from copper mines. The alga can accumulate high amounts of copper and possesses a strong antioxidant system. Here, we performed short-term transcriptomic analyses using total RNA of the alga cultivated with $10 \mu \mathrm{M}$ of copper for $0,3,6,12$ and 24 h by RNA-seq.

Results: De novo transcriptomes were assembled using the Trinity software, putative proteins were annotated and classified using Blast2GO. Differentially expressed transcripts were identified using edgeR. Transcript levels were compared by paired times 0 vs 3, 0 vs 6,0 vs 12 and 0 vs $24 \mathrm{~h}$ at an FDR $<0.01$ and Log2 Fold Change $>2$. Upregulated transcripts encode proteins belonging to photosystem II (PSII), Light Harvesting II Complex (LHCII), PSI and $\mathrm{LHCl}$, proteins involved in assembly and repair of PSII, and assembly and protection of PSI. In addition, transcripts encoding enzymes leading to $\beta$-carotene synthesis and enzymes belonging to the Calvin-Benson cycle were also increased. We further analyzed photosynthesis and carotenoid levels in the alga cultivated with $10 \mu \mathrm{M}$ of copper for 0 to $24 \mathrm{~h}$. Photosynthesis was increased from 3 to $24 \mathrm{~h}$ as well as the level of total carotenoids. The increase in transcripts encoding enzymes of the Calvin-Benson cycle suggests that $C$ assimilation may also be increased.

Conclusions: Thus, U. compressa displays a short-term response to copper stress enhancing the expression of genes encoding proteins involved in photosynthesis, enzymes involved carotenoids synthesis, as well as those belonging to the Calvin-Benson cycle, which may result in an increase in C assimilation.
\end{abstract}

Keywords: Calvin cycle, Carotenoid level, Copper, Marine alga, Photosynthesis, Ulva compressa

\section{Background}

Heavy metals such as zinc, iron, copper, and manganese are essential for plant cell viability since they are associated with proteins and enzymes such as superoxide dismutase, plastocyanin, cytochrome c oxidase, amino oxidase, polyphenol oxidase, nitrogenase, and several dehydrogenases and oxidases [1, 2]. However, excess of essential heavy metals can be toxic to cells since they induce oxidative stress leading to oxidation and destruction

\footnotetext{
* Correspondence: daniel.laporte@usach.cl; alejandra.moenne@usach.cl

${ }^{1}$ Faculty of Chemistry and Biology, University of Santiago of Chile, Av.

Libertador Bernardo O'Higgins, 3363 Santiago, Chile

Full list of author information is available at the end of the article
}

of biological macromolecules. On the other hand, some heavy metals and metalloids such as cadmium, lead, mercury, arsenic are not required for enzyme activity and they are always toxic for the cells. In particular, copper is required for photosynthetic activity in the chloroplast since it is an essential component of plastocyanin that allows transfer of electrons from cytochrome $\mathrm{b}_{6} f$ to photosystem I (PSI) reaction center. Copper is also required by cytochrome c oxidase, the final acceptor of electrons of respiratory chain, in the mitochondria and $\mathrm{Cu} / \mathrm{Zn}$ superoxide dismutase that converts superoxide anions into hydrogen peroxide, mainly in the cytosol [3-5].

(c) The Author(s). 2018 Open Access This article is distributed under the terms of the Creative Commons Attribution 4.0 International License (http://creativecommons.org/licenses/by/4.0/), which permits unrestricted use, distribution, and reproduction in any medium, provided you give appropriate credit to the original author(s) and the source, provide a link to the Creative Commons license, and indicate if changes were made. The Creative Commons Public Domain Dedication waiver (http://creativecommons.org/publicdomain/zero/1.0/) applies to the data made available in this article, unless otherwise stated. 
Regarding copper excess and photosynthesis in plants and green microalgae, it has been shown that copper toxicity is caused by the replacement of magnesium in chlorophyll by copper ions, which does not allow the efficient release of energy from chlorophyll in antenna complexes to reaction centers in Photosystem II (PSII) or directly inhibits the reaction center of PSII [3-5]. For example, the aquatic plant Ceratophyl demersum exposed to nanomolar concentrations of copper for 6 weeks showed an optimal growth at 10-30 nM of copper and an optimal activity of PSII at $2 \mathrm{nM}$ of copper [3]. Conversely, C. demersum exposed to 100-200 nM copper showed an inhibition of growth, a decrease in leaf size, fragile stems, chlorosis, and an inhibition of photochemical activity in PSII [3]. Likewise, rice plants cultivated with copper concentrations from $30 \mathrm{nM}$ to $98 \mu \mathrm{M}$ for 30 days displayed an inhibition of photosynthesis above $157 \mathrm{nM}$ mostly due to inhibition of PSII and decrease in ATP synthase activity [6]. In addition, Phaseolus vulgaris plants cultivated with 0.5 to $160 \mu \mathrm{M}$ of copper for 24 days showed an inhibition of growth and in photosynthesis efficiency [7]. Thus, it appears that plants do not tolerate copper concentrations higher than 100-200 nM due to an inhibition of photosynthesis.

On the other hand, the concentration of copper in seawater in central Chile is around $30 \mathrm{nM}$ whereas in sites of Northern Chile that receive effluents from copper mines, the concentration of copper can reach $300 \mathrm{nM}$ [8]. In these copper-polluted sites, the dominant alga species is the green macroalga Ulva compressa, which suggests that this species may tolerate copper excess. In fact, the alga has been cultivated with 10 and $50 \mu \mathrm{M}$ of copper for 7 days showing no sign of loss in viability; however, at higher concentrations of copper the viability was inhibited [9]. Until now, the effect of increasing copper concentrations on photosynthesis has not been analyzed in $U$. compressa. Regarding other macroalgae species, the brown macroalga Ectocarpus siliculosus cultivated with $1.8 \mu \mathrm{M}$ for $8 \mathrm{~h}$ showed an increase in photosynthesis efficiency, whereas it decreased with $3.7 \mu \mathrm{M}$ of copper [10]. In contrast, the red macroalga Gracilaria tenuistipitata cultivated with $16 \mathrm{nM}$ of copper showed a decrease in photosynthesis efficiency after 1,3 and 6 days of metal exposure [11]. The red macroalga Porphyra haitiensis cultivated with 0.1 to $50 \mu \mathrm{M}$ copper for 3 days showed an increase in photosynthesis when cultivated with 0.1 and $1 \mu \mathrm{M}$ copper and an increase in respiration when cultivated with 0.1 to $50 \mu \mathrm{M}$ copper [12]. Furthermore, the green macroalga Ulva flexuosa cultivated with $0.8,4$ and $8 \mu \mathrm{M}$ for 5 days did not show inhibition of photosynthesis [13]. Thus, marine macroalgae appeared to be more tolerant to copper excess than plants since photosynthesis is not inhibited or is increased with micromolar concentrations of copper.
Transcriptomic analyses using RNA-seq and microarrays in marine algae have revealed some specific responses to metals and other abiotic stresses. A microarray analysis of the brown macroalga E. siliciulosus cultivated with $1.8 \mu \mathrm{M}$ copper showed the activation of the oxylipin signaling pathway, the repression of the inositol signaling pathway, an increase or inhibition in expression of some transcription factors and an increase in expression of $\mathrm{ABC}$ transporters orthologs, P-type ATPases, ROS-detoxifying enzymes and a vanadiumdependent bromoperoxidase [14]. In addition, E. siliculosus treated with copper showed a decrease in nitrogen assimilation, as well as an increase in fatty acid content and autophagy processes. Moreover, some of the upand down-regulated genes in E. siliculosus showed identity to plant genes but a high number corresponded to yet uncharacterized genes [14]. In addition, a transcriptomic analysis performed in Ulva linza exposed to low and high temperature, high light, salt and UV-B showed an increase in expression of photoprotective proteins LhcbSR and PsbS and an increase in expression a carbonic anhydrase that improves carbon fixation. In addition, $U$. linza showed an increase in the expression of ammonium, phosphate and sulfate transporters which may improve nutrient uptake and increase in glutamate dehydrogenases, which may improve $\mathrm{N}$ fixation. Furthermore, $U$. linza showed an increase in expression of antioxidant enzymes, which may inhibit oxidative stress induced by abiotic stresses [15]. We have previously performed transcriptomic analyses in $U$. compressa cultivated with $10 \mu \mathrm{M}$ copper for 0 and $24 \mathrm{~h}$ and identified seven potential metallothioneins, antioxidant enzymes such as ascorbate peroxidase, glutathione reductase and peroxiredoxin, as well as enzymes involved in glutathione and ascorbate synthesis and their levels appeared to be increased in response to copper stress [16].

In this work, we generated de novo transcriptomes and analyzed short-term differential gene expression in $U$. compressa cultivated with $10 \mu \mathrm{M}$ of copper for $0,3,6$, 12 and $24 \mathrm{~h}$. The level of transcripts encoding proteins related with photosynthesis and enzymes of carotenoid synthesis and the Calvin-Benson cycle were increased compared with the control $(0 \mathrm{~h})$. To confirm these findings, photosynthesis and the level of carotenoids and chlorophylls were determined in the alga cultivated with $10 \mu \mathrm{M}$ of copper for 0 to $24 \mathrm{~h}$.

\section{Results}

$U$. compressa transcriptomes: Assembly, annotation, and classification of transcripts

Sequencing of cDNA libraries prepared from $U$. compressa cultivated without copper $(0 \mathrm{~h}$, control $)$ resulted in $11.4 \mathrm{M}$ of reads and those prepared from the alga cultivated with $10 \mu \mathrm{M}$ copper for $3,6,12$ and $24 \mathrm{~h}$ resulted 
in $18.4 \mathrm{M}$ of reads on average (Table 1). Reads were trimmed, and bacterial sequences were eliminated using the Bowtie 2 software by aligning the reads to bacterial reference genomes from the NCBI-RefSeq database. After quality control, the control condition presented $10.9 \mathrm{M}$ of reads and the copper-treated samples in 11.9 $\mathrm{M}$ on average (Table 1; Additional file 1: Figure S1).
Transcripts were assembled using the Trinity software and resulted in 237,116 transcripts (contigs) of 101 to 9118 nucleotides in length (Additional file 1: Figure S1). Transcripts having 200 or less nucleotides in length were removed, which resulted in 106,704 total transcripts having an average length of $868 \mathrm{bp}$ and corresponding to $45 \%$ of the initial total transcripts (Table 1). The 106,704

Table 1 Sequencing, pre-processing of reads and assembly of the Ulva compressa transcriptome

\begin{tabular}{|c|c|c|c|}
\hline Libraries & Sequence reads & Reads after QC & Reads after decontamination \\
\hline \multicolumn{4}{|c|}{ Sequencing, quality control and decontamination of reads } \\
\hline $0 \mathrm{~h}-1$ & $11,438,569$ & $11,152,558(97.50 \%)$ & $10,861,476(94.95 \%)$ \\
\hline $3 \mathrm{~h}-1$ & $20,650,530$ & $15,993,724(77.45 \%)$ & $15,768,212(76.36 \%)$ \\
\hline $3 \mathrm{~h}-2$ & $20,884,112$ & $18,978,764$ (90.88\%) & $18,756,712(89.81 \%)$ \\
\hline $6 \mathrm{~h}-1$ & $21,666,034$ & $19,744,705$ (91.13\%) & $19,436,688(89.71 \%)$ \\
\hline $6 \mathrm{~h}-2$ & $19,419,660$ & $17,691,271(91.10 \%)$ & $17,383,443(89.51 \%)$ \\
\hline $12 \mathrm{~h}-1$ & $17,354,946$ & $15,909,292(91.67 \%)$ & $15,785,199(90.96 \%)$ \\
\hline $12 \mathrm{~h}-2$ & $16,308,426$ & $12,485,489(76.56 \%)$ & $12,360,634(72.79 \%)$ \\
\hline $24 \mathrm{~h}-1$ & $12,467,371$ & $12,150,061$ (97.45\%) & $11,862,105(95.15 \%)$ \\
\hline \multicolumn{4}{|l|}{ Transcriptome assembly } \\
\hline Total genes & & 64,191 & \\
\hline Total transcripts & & $106,704(92.57 \mathrm{Mb})$ & \\
\hline Total bases & & $92,575,573(92.57 \mathrm{Mb})$ & \\
\hline Min sequence lenght & & 200 & \\
\hline Max sequence lenght & & 9118 & \\
\hline Average sequence lenght & & 868 & \\
\hline Median sequence lenght & & 542 & \\
\hline N25 lenght & & 2,28 & \\
\hline N50 lenght & & 1383 & \\
\hline N75 lenght & & 716 & \\
\hline N90 lenght & & 349 & \\
\hline N95 lenght & & 261 & \\
\hline A & & $20.95 \%$ & \\
\hline $\mathrm{T}$ & & $20.87 \%$ & \\
\hline G & & $29.18 \%$ & \\
\hline C & & $29.00 \%$ & \\
\hline$(A+T)$ & & $41.82 \%$ & \\
\hline$(G+C)$ & & $58.18 \%$ & \\
\hline N & & $0.00 \%$ & \\
\hline \multicolumn{4}{|l|}{ Transcriptome completeness } \\
\hline Completeness & & $89.59 \%$ & \\
\hline Complete CEG & & 265 & \\
\hline Complete and single copy & & 123 & \\
\hline Complete and multi-copy & & 142 & \\
\hline Fragmented CEGs & & 85 & \\
\hline Missing CEGs & & 79 & \\
\hline Total CEGs database & & 429 & \\
\hline
\end{tabular}


transcripts represent 64,191 genes with a N50 value of $1383 \mathrm{bp}$, average GC content of $58.18 \%$, where $81.59 \%$ of transcripts were present in Core Eukaryotic Genes datasets (CEGs and OrthoDB databases) (Table 1).

Transcripts were translated into amino acids using BlastX and those having an e-value of $1 \mathrm{e}^{-3}$ or less were selected. Transcripts were annotated using UniprotKB database with Blat2GO software and 40,037 protein sequences were obtained of which 36,094 were selected having an e-value of $1 \mathrm{e}^{-6}$ or lower. These 36,094 proteins are involved in different biological processes corresponding to: $12.210(11 \%)$ associated with macromolecules metabolic processes; 10.901 (10\%) with organic nitrogen metabolic processes; 9.701 (9\%) with cellular macromolecule processes; $9.291(8 \%)$ with cellular nitrogen compound metabolic processes; 8.362 (8\%) with organic substance biosynthetic processes; 8.131 (7\%) with cellular biosynthetic processes; 7.878 (7\%) with protein metabolic processes; 7.769 (7\%) with organic cyclic metabolic processes; 7.455 (7\%) in heterocycle metabolic processes; 7.499 (7\%) with aromatic compound metabolic processes; 6.685 (6\%) with nucleobase-containing compound metabolic processes; 4.549 (4\%) with transport; 4.035 (4\%) with phosphorous metabolic processes; 3.073 (3\%) with organic acid metabolic processes and 2.961 (3\%) with organelle organization processes (Fig. 1). Thus, at least $21 \%$ of the proteins are involved in secondary metabolism, $4 \%$ in transport and $3 \%$ in organelle organization. In addition, proteins were classified according to their molecular function and cellular component (Additional file 2: Figure S2).

Thirty-two thousand and 162 protein sequences were selected using BLAST Top-Hit species and a database of proteins belonging to 29 model species to analyze the similarity to plant, animal, protist, fungal, and prokaryote proteins. Results indicate that 17,140 proteins (53.3\%) are similar to plant proteins; 9570 (29.8\%) to animal proteins; 2891 (9\%) to fungal proteins; $1772(5.5 \%)$ to protist proteins and 789 (2.5\%) to prokaryote proteins (Fig. 2). These results suggest that almost $30 \%$ of $U$. compressa proteins are related to animal proteins corresponding to 11 animal species including human, mouse and rat (Fig. 2) and 53\% with plant proteins.

\section{Transcripts differentially expressed in response to copper stress}

Transcripts were filtered by FDR of 0.01 or lower, and a Log2 Fold Change higher than 2. From 106,704 transcripts, only 23,978 were differentially expressed. When clustering samples by their differential expression profiles, it was observed that samples taken at 0 and $24 \mathrm{~h}$ had similar differential expression patterns, while samples at 3, 6, and $12 \mathrm{~h}$ showed time-specific profiles. All biological replicates were more similar to each other than to other samples (Fig. 3a). This was also true when comparing the expression profiles of all transcripts, not only those differentially expressed (Fig. 3b). This suggests that copper has a measurable and specific impact upon gene expression, indicating that those differentially expressed genes might reveal molecular mechanisms by which $U$. compressa copes with copper excess.

\section{Transcripts with increased level encode proteins involved} in assembly, repair and protection of photosystems

The level of transcripts encoding subunits PsbA, PsbB, PsbC, PsbD, PsbJ, PsbO, PsbP, PsbR, PsbS, PsbW and PsbZ were increased in response to copper stress (Table 2; Fig. 4). In addition, transcripts encoding proteins belonging to the Light Harvesting Complex II (LHCII) involved in chlorophyll a/b-binding corresponding to Lhcb1, Lhb2 and Lhb4, present in plants, and

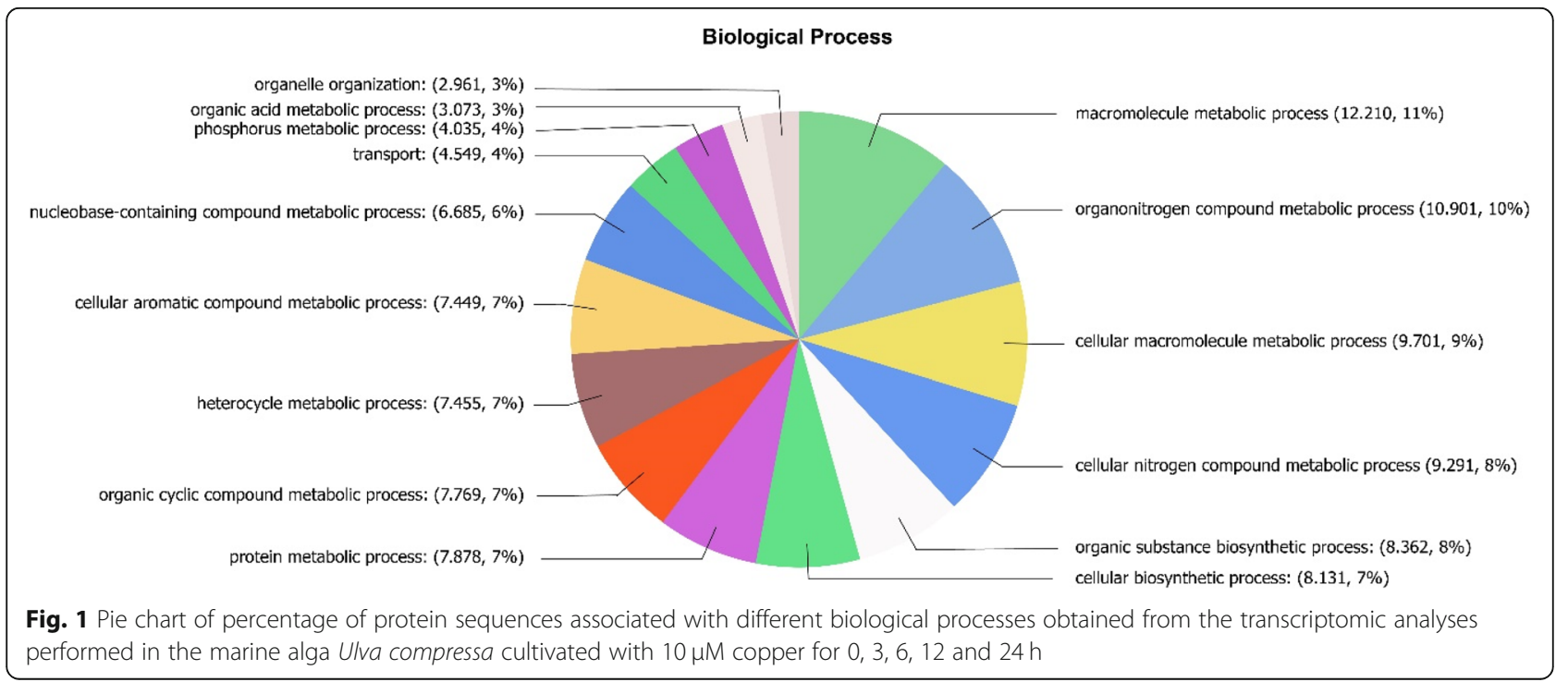




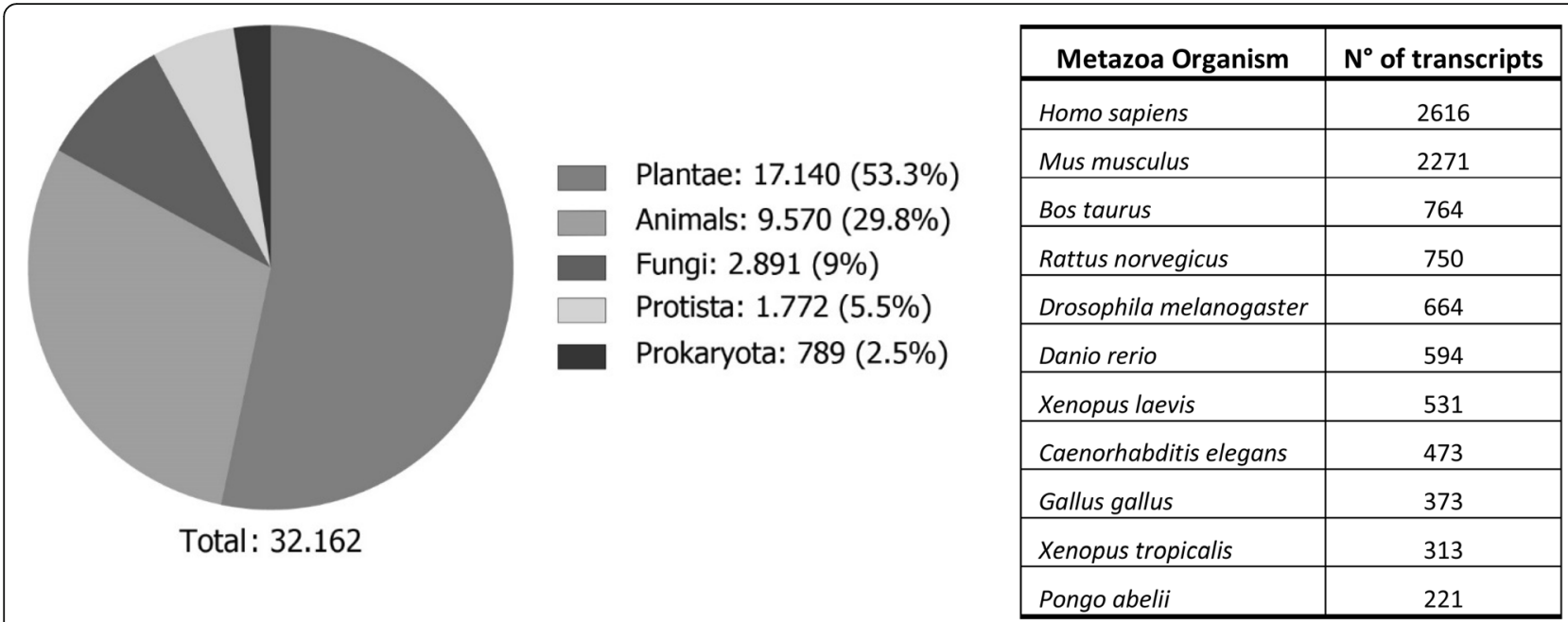

Fig. 2 Pie chart of percentage of protein sequences associated with different classes of organisms obtained from the transcriptomic analyses performed in the marine alga Ulva compressa cultivated with $10 \mu \mathrm{M}$ copper for $0,3,6,12$ and $24 \mathrm{~h}$

those encoding proteins involved in fucoxanthin and chlorophyll a/c binding corresponding to LhcbA and LhcB, present in diatoms, were also up-regulated (Table 2; Fig. 4). Moreover, transcripts encoding enzymes solanesyl diphosphate synthase, involved in the synthesis of the terpene tail of plastoquinone as well as iron-sulfur subunit of cytochrome b6f complex (PetC) were increased (Table 2; Fig. 4). Furthermore, transcripts encoding proteins of PSI, PsaA, PsaD, PsaE, PsaF, PsaG, psaK and PsaO, as well as ferredoxin-NADP reductase (PetH) and
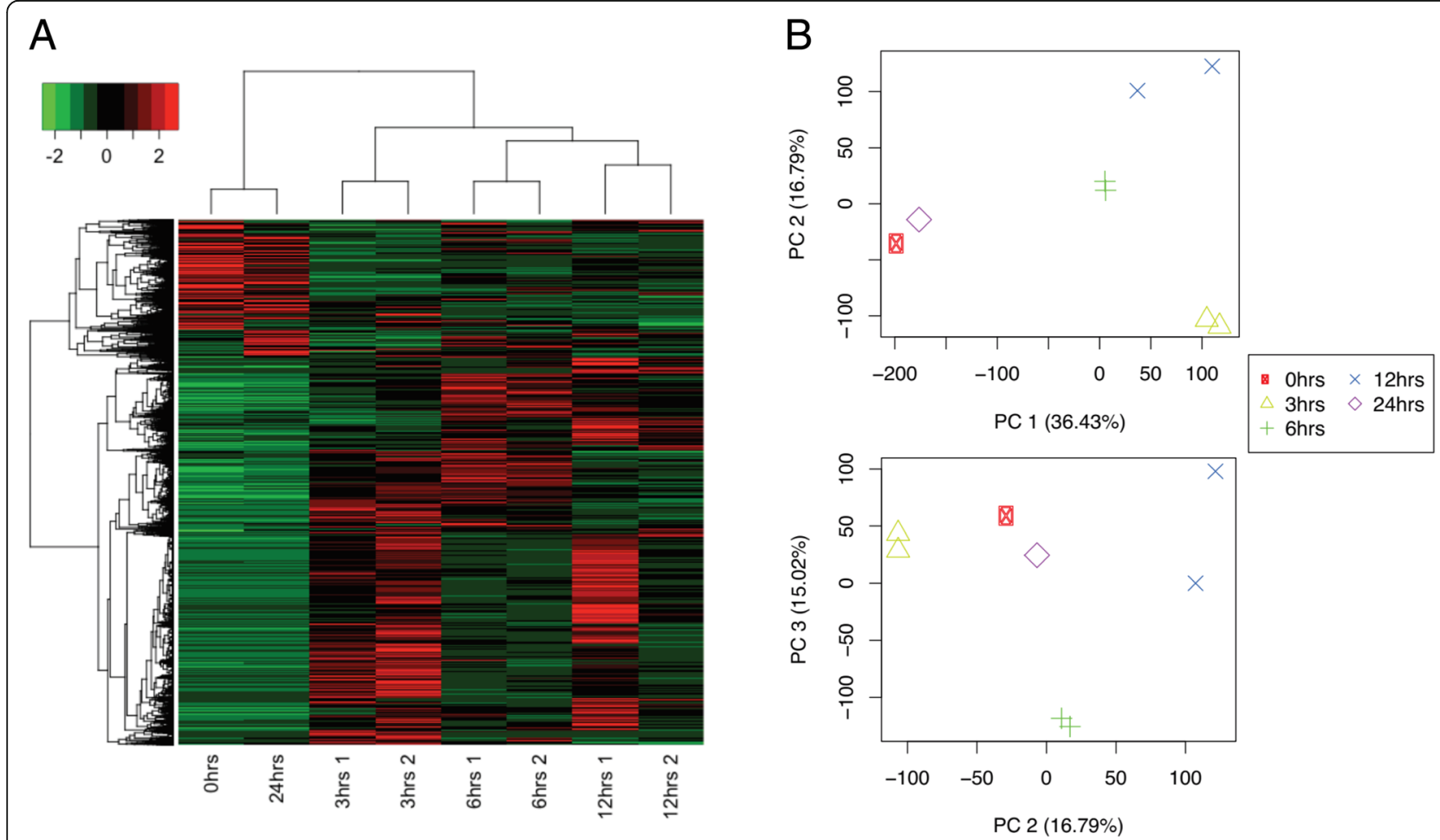

Fig. 3 Gene expression profile and sample-to-sample distance relationships. a Heatmap representing the expression levels (read counts) of the differentially expressed transcripts (FDR < 0.01, FC > 2) across samples: 0, 3, 6, and $12 \mathrm{~h} \mathrm{("3} \mathrm{h} \mathrm{1",} \mathrm{"3} \mathrm{h} \mathrm{2",} \mathrm{"6} \mathrm{h} \mathrm{1",} \mathrm{"6} \mathrm{h2",} \mathrm{"12} \mathrm{h} \mathrm{1"} \mathrm{and} \mathrm{"12} \mathrm{h} \mathrm{2").} \mathrm{Read} \mathrm{counts}$ were mean-centered and scaled, and the resulting values were represented in a green red false color scale (green = underexpressed; red =overexpressed). Columns and rows were clustered by the Spearman correlation coefficient among samples and transcripts, respectively. b Principal component analysis (PCA) showing how the samples are grouped based on transcripts CPM (counts per million) values at each sample. Top plot shows the first and second components (53.22\% of variance), and bottom plot shows the second and third components (31.81\% of variance) 
Table 2 Up-regulated genes related to photosynthesis

\begin{tabular}{|c|c|c|c|}
\hline Process & ID_Transcript & Proteins & Fold change \\
\hline \multirow[t]{14}{*}{$\overline{\mathrm{PS} \|}$} & TRINITY_DN28356_c0_g7_i2 & PsbA & 3.3 \\
\hline & TRINITY_DN26114_c0_g9_i1 & PsbB & 2.0 \\
\hline & TRINITY_DN24036_c0_g1_i1 & PsbC & 2.5 \\
\hline & TRINITY_DN51574_C0_g1_i1 & PsbJ & 3.2 \\
\hline & TRINITY_DN25152_c1_g6_i1 & Psbo & 3.0 \\
\hline & TRINITY_DN25152_c1_g3_i1 & PsbO & 2.8 \\
\hline & TRINITY_DN23656_c0_g2_i2 & PsbP & 2.7 \\
\hline & TRINITY_DN30969_c0_g1_i1 & PsbP & 2.9 \\
\hline & TRINITY_DN134452_c0_g1_i1 & PsbR & 2.9 \\
\hline & TRINITY_DN24151_c1_g3_i1 & PsbS & 2.2 \\
\hline & TRINITY_DN22768_c0_g2_i1 & PsbW & 3.0 \\
\hline & TRINITY_DN21681_c1_g1_i2 & PsbW & 3.3 \\
\hline & TRINITY_DN21681_c1_g1_i1 & PsbW & 3.2 \\
\hline & TRINITY_DN22451_c0_g1_i5 & Psbz & 2.8 \\
\hline \multirow[t]{16}{*}{ LHCII } & TRINITY_DN28384_C2_g10_i1 & Chlorophyll a-b binding protein 1D (Ihcb1) & 3.3 \\
\hline & TRINITY_DN24974_c1_g9_i1 & Chlorophyll a-b binding protein 1D (Ihcb1) & 2.9 \\
\hline & TRINITY_DN28161_c1_g6_i2 & Chlorophyll a-b binding protein 8 (Ihcb2-like) & 3.2 \\
\hline & TRINITY_DN23399_c0_g1_i2 & Chlorophyll a-b binding protein CP29 (Ihcb4) & 2.9 \\
\hline & TRINITY_DN23399_C0_g1_i3 & Chlorophyll a-b binding protein CP29 (lhcb4) & 2.9 \\
\hline & TRINITY_DN23399_c0_g1_i1 & Chlorophyll a-b binding protein CP29 (Ihcb4) & 2.8 \\
\hline & TRINITY_DN25769_c2_g3_i4 & Chlorophyll a-b binding protein L1818 (Ihcb4-like) & 3.4 \\
\hline & TRINITY_DN25769_c2_g3_i2 & Chlorophyll a-b binding protein L1818 (Ihcb4-like) & 3.1 \\
\hline & TRINITY_DN23036_c1_g1_i8 & Fucoxanthin binding protein A & 2.8 \\
\hline & TRINITY_DN23036_c1_g1_i5 & Fucoxanthin binding protein $\mathrm{A}$ & 2.8 \\
\hline & TRINITY_DN28382_c2_g1_i8 & Fucoxanthin binding protein B & 3.0 \\
\hline & TRINITY_DN28382_C2_g1_i7 & Fucoxanthin binding protein B & 2.7 \\
\hline & TRINITY_DN25548_C0_g1_i1 & Solanesyl diphosphate synthase 1 & 3.2 \\
\hline & TRINITY_DN25548_c0_g1_i2 & Solanesyl-diphosphate synthase 3 & 3.3 \\
\hline & TRINITY_DN25548_c0_g1_i3 & Solanesyl-diphosphate synthase 3 & 3.2 \\
\hline & TRINITY_DN25548_c0_g1_i7 & Solanesyl-diphosphate synthase 3 & 3.4 \\
\hline \multirow[t]{5}{*}{ Cyt b6-f } & TRINITY_DN27161_C0_g1_i10 & Iron-sulfur subunit (petC) & 3.7 \\
\hline & TRINITY_DN27161_C0_g1_i1 & Iron-sulfur subunit (petC) & 3.1 \\
\hline & TRINITY_DN27161_C0_g1_i7 & Iron-sulfur subunit (petC) & 2.7 \\
\hline & TRINITY_DN27161_C0_g1_i13 & Iron-sulfur subunit (petC) & 2.6 \\
\hline & TRINITY_DN27161_C0_g1_i12 & Iron-sulfur subunit (petC) & 2.5 \\
\hline \multirow[t]{9}{*}{ PSI } & TRINITY_DN26298_c1_g1_i5 & PsaA & 3.4 \\
\hline & TRINITY_DN26298_c1_g1_i1 & PsaA & 3.2 \\
\hline & TRINITY_DN26298_c1_g1_i6 & PsaA & 3.0 \\
\hline & TRINITY_DN26298_c1_g1_i3 & PsaA & 2.6 \\
\hline & TRINITY_DN24286_c0_g3_i1 & PsaD & 1.9 \\
\hline & TRINITY_DN21945_c0_g2_i1 & PsaE & 3.3 \\
\hline & TRINITY_DN23092_C0_g3_i1 & PsaF & 3.6 \\
\hline & TRINITY_DN23521_c0_g1_i1 & PsaG & 3.6 \\
\hline & TRINITY_DN23521_c0_g1_i2 & PsaG & 3.3 \\
\hline
\end{tabular}


Table 2 Up-regulated genes related to photosynthesis (Continued)

\begin{tabular}{|c|c|c|c|}
\hline Process & ID_Transcript & Proteins & Fold change \\
\hline & TRINITY_DN25932_c0_g1_i3 & Psak & 3.6 \\
\hline & TRINITY_DN21897_c0_g2_i1 & PsaO & 3.4 \\
\hline & TRINITY_DN26200_c0_g3_i1 & Ferredoxin-NADP reductase (petH) & 2.9 \\
\hline & TRINITY_DN24658_c0_g1_i1 & Ferredoxin-2 (petF) & 2.8 \\
\hline \multirow[t]{16}{*}{$\mathrm{LHCl}$} & TRINITY_DN24974_c1_g7_i2 & Chlorophyll a-b binding protein 1 & 2.8 \\
\hline & TRINITY_DN28384_C2_g5_i2 & Chlorophyll a-b binding protein 1 & 3.3 \\
\hline & TRINITY_DN28268_c0_g2_i6 & Chlorophyll a-b binding protein 1 & 3.2 \\
\hline & TRINITY_DN28268_c0_g2_i9 & Chlorophyll a-b binding protein 1 & 3.0 \\
\hline & TRINITY_DN28268_c0_g2_i7 & Chlorophyll a-b binding protein 1 & 2.9 \\
\hline & TRINITY_DN28384_C2_g17_i1 & Chlorophyll a-b binding protein 1 & 2.8 \\
\hline & TRINITY_DN26721_c1_g6_i1 & Chlorophyll a-b binding protein 1B-21 (Ihca1) & 3.2 \\
\hline & TRINITY_DN26721_c1_g6_i2 & Chlorophyll a-b binding protein 1B-21 (Ihca1) & 3.5 \\
\hline & TRINITY_DN27296_c2_g4_i2 & Chlorophyll a-b binding protein 5 (Ihca1-like) & 2.6 \\
\hline & TRINITY_DN28268_c0_g2_i3 & Chlorophyll a-b binding protein 5 (Ihca1-like) & 2.5 \\
\hline & TRINITY_DN25309_c0_g1_i2 & Chlorophyll a-b binding protein 5 (Ihca1-like) & 2.5 \\
\hline & TRINITY_DN27296_c2_g1_i11 & Chlorophyll a-b binding protein 5 (Ihca1-like) & 2.2 \\
\hline & TRINITY_DN25604_C0_g1_i1 & Chlorophyll a-b binding protein 5 (Ihca1-like) & 2.6 \\
\hline & TRINITY_DN25604_C0_g1_i4 & Chlorophyll a-b binding protein 5 (Ihca1-like) & 3.4 \\
\hline & TRINITY_DN28161_c1_g6_i3 & Chlorophyll a-b binding protein 8 (Ihca1-like) & 2.1 \\
\hline & TRINITY_DN28161_c1_g6_i4 & Chlorophyll a-b binding protein 8 (Ihca1-like) & 2.0 \\
\hline \multirow[t]{2}{*}{ ATP synthase } & TRINITY_DN23229_c0_g3_i1 & ATP synthase subunit b' & 3.4 \\
\hline & TRINITY_DN24803_c0_g1_i1 & ATP synthase gamma chain & 1.4 \\
\hline \multirow[t]{22}{*}{ Repair of PSII } & TRINITY_DN26385_c1_g4_i3 & MET1 & 3.5 \\
\hline & TRINITY_DN25782_CO_g1_i2 & MET1 & 3.4 \\
\hline & TRINITY_DN26385_c1_g4_i2 & MET1 & 3.3 \\
\hline & TRINITY_DN27340_c1_g3_i2 & Deg/HtrA protease Do-like 1 & 3.3 \\
\hline & TRINITY_DN26676_c1_g1_i1 & Deg/HtrA protease Do-like 1 & 3.3 \\
\hline & TRINITY_DN27340_c1_g3_i3 & Deg/HtrA protease Do-like 1 & 3.2 \\
\hline & TRINITY_DN26676_c1_g1_i12 & Deg/HtrA protease Do-like 1 & 3.2 \\
\hline & TRINITY_DN27340_c1_g3_i4 & Deg/HtrA protease Do-like 1 & 3.2 \\
\hline & TRINITY_DN27340_c1_g3_i1 & Deg/HtrA protease Do-like 1 & 3.1 \\
\hline & TRINITY_DN25574_c0_g1_i4 & Deg/HtrA protease Do-like 2 & 2.9 \\
\hline & TRINITY_DN25574_C0_g1_i7 & Deg/HtrA protease Do-like 2 & 2.7 \\
\hline & TRINITY_DN18665_c0_g1_i1 & Deg/HtrA protease Do-like 5 & 3.0 \\
\hline & TRINITY_DN28204_c1_g1_i2 & Deg/HtrA protease Do-like 8 & 2.7 \\
\hline & TRINITY_DN25743_c0_g2_i1 & EGY1 & 3.2 \\
\hline & TRINITY_DN25743_c0_g2_i2 & EGY1 & 3.0 \\
\hline & TRINITY_DN25743_c0_g2_i3 & EGY1 & 2.9 \\
\hline & TRINITY_DN23341_c0_g1_i1 & ATP-dependent zinc metalloprotease FTSH 1 & 3.2 \\
\hline & TRINITY_DN27493_c2_g1_i7 & ATP-dependent zinc metalloprotease FTSH 2 & 3.1 \\
\hline & TRINITY_DN27493_c2_g1_i1 & ATP-dependent zinc metalloprotease FTSH 2 & 3.1 \\
\hline & TRINITY_DN27493_c2_g1_i11 & ATP-dependent zinc metalloprotease FTSH 2 & 3.1 \\
\hline & TRINITY_DN28584_c2_g1_i4 & ATP-dependent zinc metalloprotease FTSH 5 & 3.3 \\
\hline & TRINITY_DN27493_c2_g4_i1 & ATP-dependent zinc metalloprotease FTSH 8 & 2.9 \\
\hline
\end{tabular}


Table 2 Up-regulated genes related to photosynthesis (Continued)

\begin{tabular}{|c|c|c|c|}
\hline Process & ID_Transcript & Proteins & Fold change \\
\hline & TRINITY_DN27493_c2_g4_i3 & ATP-dependent zinc metalloprotease FTSH 8 & 2.9 \\
\hline & TRINITY_DN24421_C0_g1_i1 & THYLAKOID FORMATION 1 & 3.2 \\
\hline & TRINITY_DN22196_C0_g2_i1 & EMBRYO SAC DEVELOPMENT ARREST 3 & 2.9 \\
\hline & TRINITY_DN25705_c1_g2_i2 & Palmitoyl-monogalactosyldiacylglycerol delta-7 desaturase & 2.6 \\
\hline \multirow[t]{13}{*}{ Assembly of PSII } & TRINITY_DN23616_C0_g1_i4 & YCF4 & 3.3 \\
\hline & TRINITY_DN23616_c0_g1_i2 & YCF4 & 2.1 \\
\hline & TRINITY_DN22135_c0_g2_i3 & Ycf3 interacting Protein & 2.9 \\
\hline & TRINITY_DN27520_c0_g2_i3 & KEA1 & 2.7 \\
\hline & TRINITY_DN24215_C0_g1_i3 & UPF0187 protein & 2.7 \\
\hline & TRINITY_DN25274_c0_g1_i1 & TAB2 homolog & 3.2 \\
\hline & TRINITY_DN25675_c1_g3_i1 & Serine/threonine-protein kinase STN7 & 2.7 \\
\hline & TRINITY_DN25616_C0_g2_i1 & PPH1 2C 57 & 3.1 \\
\hline & TRINITY_DN28540_C1_g8_i2 & PGR5 1A & 3.5 \\
\hline & TRINITY_DN28540_c1_g2_i2 & PGR5 1A & 3.1 \\
\hline & TRINITY_DN27605_c0_g1_i2 & PGR5 1A & 2.9 \\
\hline & TRINITY_DN26853_c0_g1_i1 & PGR5 1B & 3.3 \\
\hline & TRINITY_DN20751_C0_g2_i1 & PGR5 & 3.3 \\
\hline
\end{tabular}

ferredoxin (PetF) were increased (Table 2; Fig. 4). In addition, transcripts encoding proteins belonging to the Light Harvesting Complex I ( $\mathrm{LHCI}$ ) corresponding to Lhca1, Lhca5 and Lhca8 were also increased in response to copper excess (Table 2; Fig. 4). Finally, transcripts encoding subunit b' and gamma subunits of ATP synthase complex were also increased (Table 2; Fig. 4).

Transcripts encoding proteins involved in repair of PSII were also up-regulated such as MET1, involved disassemble and reassemble of PSII to remove damaged PsbA (D1). In addition, the serine proteases Deg/HtrA (Do)-like proteases 1, 2, 5 and 8, the metalloprotease EGY1 and the ATP-dependent proteases FTSH 1, 2, 5 and 8 involved in the degradation of damaged PsbA, and other oxidized subunits of PSII, were also up-regulated (Table 2). Moreover, transcripts encoding proteins involved in chloroplast repair such as Thylakoid
Formation 1 (THF1), involved in the formation of the supramolecular complex among PSII and LHCII, Embryo Sac Development Arrests 3 (ESD3), involved in thylakoid formation, and the enzyme palmitoylmonogalactosyl diacylglycerol delta 7-desaturase involved in the synthesis of chloroplast fatty acids were also increased (Table 2). On the other hand, transcripts encoding proteins involved in assembly and stabilization of PSI such as Ycf-4 and Ycf-3-interacting protein that cooperate with Ycf3 in the assembly of PSI were enhanced. In addition, the potassium antiporter KEA1, required for PSI formation, UPF0187, involved in the stabilization of PSI, TAB2, involved in translation of PsaB, the kinase STN7, involved in phosphorylation of the LHCII that allows its migration of subunits of PSII to PSI, and the phosphatase PPH1 (2C57), involved in the dephosphorylation of LHCII that increase the

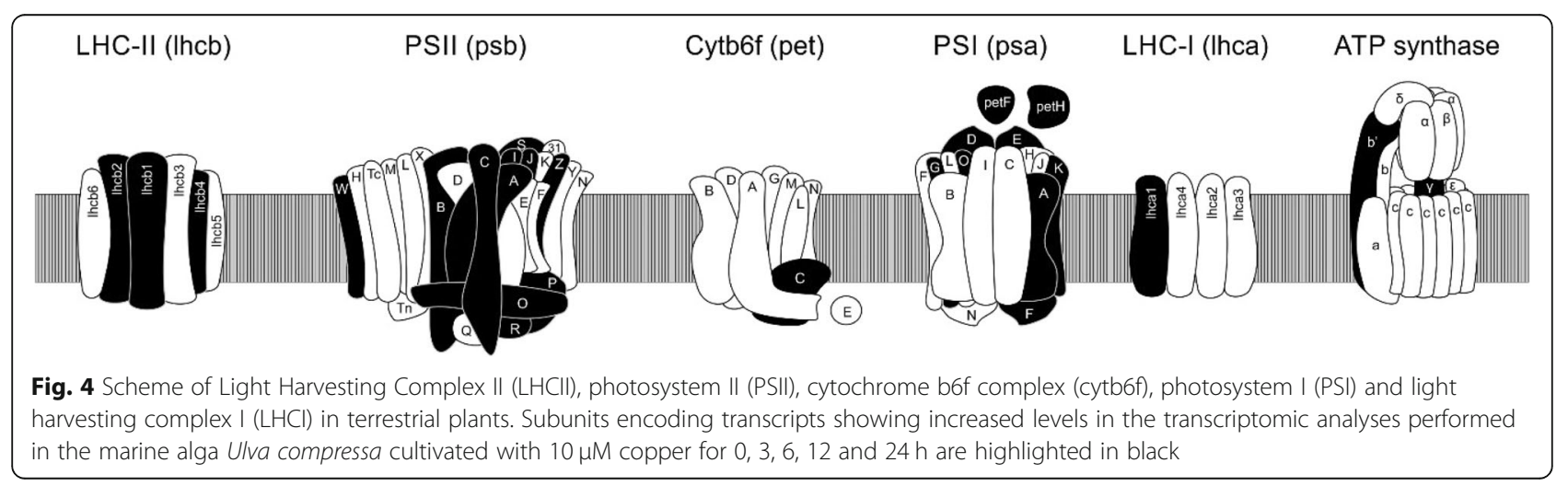


migration of Lhcb1 and Lhcb2 subunits to PSI, were also increased. Furthermore, PGR1 and PGR5, two proteins involved in the control of the cyclic electron flow around PSI and protecting PSI against photo-oxidation were also up-regulated (Table 2).

\section{Transcripts with increased levels encode enzymes involved} in carotenoid synthesis and the Calvin-Benson cycle

The level of transcripts encoding the enzymes geranylgeranyl diphosphate synthase (GGDS), an enzyme that synthesize geranylgeranyl pyrophosphate; phytoene synthase (PS), that synthesize phytoene; phytoene desaturase (PD), that synthesize 5 -carotene; carotene desaturase (CD), that synthesize lycopene, and lycopene $\beta$-cyclase (LC), that synthesize $\beta$-carotene were increased (Table 3). In addition, the level of transcripts encoding enzymes of the Calvin-Benson cycle such as the small subunit $(\mathrm{RbcS})$ of ribulose 1,5 biphosphate carboxylase/oxygenase (rubisco), ribulose phosphate 3 epimerase (RP3E), transketolase (TK), glyceraldehyde 3 phosphate dehydrogenase (G3PDH), fructose 1,6 biphosphatase (FBP), sedoheptulose 1,7 biphosphatase (SHBP), phosphoribulokinase (PRK), phosphoglycerate kinase (PGK) and ribose 5-phophate isomerase (R5PI) were also up-regulated (Table 3).

\section{Kinetics of the increase of transcripts encoding proteins of photosystems, and enzymes of carotenoid synthesis and Calvin-Benson cycle}

The levels of transcripts encoding the subunits of PSII showing the higher increases were those encoding the core subunit PsbA (D1) that increased with a maximal level at $6 \mathrm{~h}$ of copper exposure and slowly decreased until $24 \mathrm{~h}$ of exposure and the subunit PsbW, a small subunit of $6.1 \mathrm{kDa}$ closely associated with PSII reaction center, that showed maximal increases at 3 and $12 \mathrm{~h}$ of copper exposure (Fig. 5a). In the case of transcripts related to PSI, the higher increases were those encoding PGR5-1A that stimulate electron transfer from ferredoxin to plastoquinone and control the electron flow around PSI, and their level increased at $6 \mathrm{~h}$ and decreased until $24 \mathrm{~h}$ (Fig. 5b). Regarding carotenoids synthesis, transcripts encoding GGDS, PS, PD, $\mathrm{CD}$ and $\mathrm{LC}$ showed an increase at $3 \mathrm{~h}$ of copper exposure and a subsequent increase at 12 of exposure (Fig. 5c). Regarding enzymes of the Calvin-Benson cycle, transcripts encoding G3PDH increased at $3 \mathrm{~h}$ of copper exposure, decreased and then increased again at $24 \mathrm{~h}$, and those encoding RP3E, PRK, TK and the small chain of rubisco increased at $3 \mathrm{~h}$ of exposure and decrease and remained until $6 \mathrm{~h}$ and remained stable until $24 \mathrm{~h}$ (Fig. 5d).

\section{Copper-induced increase in photosynthesis and carotenoid levels}

The increase in transcripts encoding subunits of PSII and PSI as well as repair proteins of PSII and assembly and protection of PSI suggests that photosynthesis may be increased in $U$. compressa exposed to copper excess until $24 \mathrm{~h}$. In fact, the alga cultivated in control conditions displayed an oxygen production of $25 \mathrm{nmoles} \mu \mathrm{L}^{-1} \mathrm{~min}^{-1}$ that decreased reaching a level of $14.2 \mathrm{nmoles} \mu \mathrm{L}^{-1} \mathrm{~min}^{-1}$ at $6 \mathrm{~h}$ of exposure and continued to decrease until $24 \mathrm{~h}$ reaching a level of $12.8 \mathrm{nmoles} \mu \mathrm{L}^{-1} \min ^{-1}$ at $24 \mathrm{~h}$ (Fig. 6a). In contrast, the alga exposed to $10 \mu \mathrm{M}$ copper showed an initial decrease in oxygen production, but it level remained higher than in control conditions reaching a level of $18.3 \mathrm{nmoles} \mu \mathrm{L}^{-1} \mathrm{~min}^{-1}$ at $6 \mathrm{~h}$ of exposure and 17.9 nmoles $\mu \mathrm{L}^{-1} \mathrm{~min}^{-1}$ at $24 \mathrm{~h}$, which represents an increase of 1.4 times compared to the control at $24 \mathrm{~h}$ (Fig. 6a).

The level of carotenoids in the alga cultivated in control conditions was $618 \mu \mathrm{g} \mathrm{mg}^{-1}$ of FT, which remained unchanged until $24 \mathrm{~h}$ (Fig. 6b). In the alga treated with copper, the level of carotenoids increased reaching a level of $841 \mu \mathrm{g} \mathrm{mg}^{-1}$ of FT at $6 \mathrm{~h}$ of exposure and decreased until at 24 of exposure reaching a level of $735 \mu \mathrm{g} \mathrm{mg}{ }^{-1}$ of FT which represents an increase 1.2 times compared to the control at $24 \mathrm{~h}$ (Fig. 6b). In addition, the level of chlorophylls $a$ and $b$ (Fig. 6c-d) did not change in the alga exposed to copper excess compare to the control condition. The level of chlorophyll a was $108 \mu \mathrm{g} \mathrm{mg}^{-1}$ in control and treated samples at time 0 and it was $139 \mu \mathrm{g} \mathrm{mg}^{-1}$ at $24 \mathrm{~h}$ of exposure (Fig. 6c). The level of chlorophyll b was $45 \mu \mathrm{g}$ $\mathrm{mg}^{-1}$ at time 0 in control and treated samples; this level was $26 \mu \mathrm{g} \mathrm{mg}^{-1}$ in control samples and $50 \mu \mathrm{g} \mathrm{mg}^{-1}$ in treated samples at $24 \mathrm{~h}$ of exposure but these levels were not significantly different (Fig. 6d). Thus, copper stress induced an increase in photosynthesis and in the level of carotenoids in $U$. compressa that is regulated, at least in part, at transcriptional level.

\section{Discussion}

In this work, we showed that the marine alga $U$. compressa cultivated with $10 \mu \mathrm{M}$ copper for $24 \mathrm{~h}$ displays an increase in transcripts encoding subunits of PSII, LHCII, PSI and LHCI, as well as in proteins and enzymes involved in the assembly and repair of PSII, and in the assembly and protection of PSI. The increase in transcripts encoding proteins involved in assembly, protection and repair photosystems, correlated with an increase in photosynthesis in the alga cultivated with $10 \mu \mathrm{M}$ copper for 0 to $24 \mathrm{~h}$. Thus, copper induces an increase in photosynthesis which is due, at least in part, to an increase in gene expression. The latter results are in agreement with those obtained in the red alga Porphyra haitiensis that showed an increase in photosynthesis when cultivated with 0.1 and $1 \mu \mathrm{M}$ copper for 3 days [12], the brown macroalga E. siliculosus cultivated with $1.8 \mu \mathrm{M}$ for $8 \mathrm{~h}$ that displayed an increase in PSII efficiency [10] and the green macroalga Ulva flexuosa 
Table 3 Up-regulated genes related to Calvin-Benson cycle

\begin{tabular}{|c|c|c|c|}
\hline Process & ID_Transcript & Proteins & Fold change \\
\hline \multirow[t]{35}{*}{ Calvin-Benson cycle } & TRINITY_DN26739_c1_g1_i11 & Ribulose bisphosphate carboxylase small chain 1 & 3.5 \\
\hline & TRINITY_DN26739_c1_g1_i6 & Ribulose bisphosphate carboxylase small chain 1 & 3.4 \\
\hline & TRINITY_DN26739_c1_g1_i10 & Ribulose bisphosphate carboxylase small chain 1 & 3.2 \\
\hline & TRINITY_DN26739_C1_g1_i1 & Ribulose bisphosphate carboxylase small chain 1 & 3.0 \\
\hline & TRINITY_DN26739_c1_g1_i8 & Ribulose bisphosphate carboxylase small chain 1 & 3.1 \\
\hline & TRINITY_DN24974_C1_g8_i2 & Ribulose-phosphate 3-epimerase & 3.2 \\
\hline & TRINITY_DN24974_C1_g8_i1 & Ribulose-phosphate 3-epimerase & 3.1 \\
\hline & TRINITY_DN24974_c1_g5_i2 & Ribulose-phosphate 3-epimerase & 3.0 \\
\hline & TRINITY_DN24974_c1_g5_i1 & Ribulose-phosphate 3-epimerase & 2.9 \\
\hline & TRINITY_DN26523_c0_g6_i1 & Transketolase-2 & 3.4 \\
\hline & TRINITY_DN26523_c0_g5_i1 & Transketolase & 2.3 \\
\hline & TRINITY_DN26020_c1_g2_i2 & Glyceraldehyde-3-phosphate dehydrogenase & 3.2 \\
\hline & TRINITY_DN28111_C0_g1_i3 & Glyceraldehyde-3-phosphate dehydrogenase & 3.2 \\
\hline & TRINITY_DN28111_C0_g6_i2 & Glyceraldehyde-3-phosphate dehydrogenase & 3.1 \\
\hline & TRINITY_DN25377_c1_g4_i1 & Glyceraldehyde-3-phosphate dehydrogenase & 3.0 \\
\hline & TRINITY_DN28111_C0_g1_i5 & Glyceraldehyde-3-phosphate dehydrogenase & 2.7 \\
\hline & TRINITY_DN25377_c0_g1_i1 & Glyceraldehyde-3-phosphate dehydrogenase & 2.7 \\
\hline & TRINITY_DN25438_C0_g3_i2 & Fructose-1,6-bisphosphatase & 3.2 \\
\hline & TRINITY_DN25438_c0_g2_i2 & Fructose-1,6-bisphosphatase & 3.2 \\
\hline & TRINITY_DN25438_C0_g2_i1 & Fructose-1,6-bisphosphatase & 3.1 \\
\hline & TRINITY_DN25498_c1_g1_i1 & Seudoheptulose-1,7-bisphosphatase & 3.2 \\
\hline & TRINITY_DN25498_c1_g2_i2 & Seudoheptulose-1,7-bisphosphatase & 3.0 \\
\hline & TRINITY_DN28545_c0_g3_i2 & Phosphoribulokinase & 3.0 \\
\hline & TRINITY_DN24724_C0_g2_i4 & Phosphoribulokinase & 2.7 \\
\hline & TRINITY_DN20744_c0_g1_i2 & Phosphoglycerate kinase & 2.9 \\
\hline & TRINITY_DN19258_C0_g2_i1 & Pyruvate phosphate dikinase & 2.9 \\
\hline & TRINITY_DN134423_C0_g1_i1 & Pyruvate phosphate dikinase & 2.9 \\
\hline & TRINITY_DN28070_c1_g1_i2 & Ribose-5-phosphate isomerase 3 & 3.1 \\
\hline & TRINITY_DN25979_c1_g4_i1 & BC1 complex kinase 1 & 3.1 \\
\hline & TRINITY_DN25979_c1_g4_i2 & BC1 complex kinase 1 & 3.1 \\
\hline & TRINITY_DN24548_C0_g4_i1 & Geranylgeranyl diphosphate synthase & 2.9 \\
\hline & TRINITY_DN25865_c0_g2_i3 & Phytoene synthase & 3.1 \\
\hline & TRINITY_DN23375_c0_g1_i3 & 15-cis-phytoene desaturase & 3.0 \\
\hline & TRINITY_DN25489_c0_g1_i1 & Zeta-carotene desaturase & 3.3 \\
\hline & TRINITY_DN22033_c0_g1_i1 & Lycopene beta cyclase & 3.0 \\
\hline
\end{tabular}

cultivated $8 \mu \mathrm{M}$ for 5 days that did not showed inhibition of photosynthesis efficiency [13]. Thus, it appeared that red, brown and green marine macroalgae are able to tolerate micromolar concentrations of copper by protecting photosynthesis, but the level of tolerance to copper excess depends on the algal species.

In addition, the increase in photosynthesis observed in $U$. compressa agrees with the increase in the level of carotenoids located in LHCII and LHCI. It is important to mention that increased transcripts encode all the enzymes required for the synthesis $\beta$-carotene from isopentenyl diphosphate. It is important to mention that carotenoids are involved in the protection of photosynthetic apparatus by quenching directly chlorophyll triplet states, thus, inhibiting singlet oxygen formation. In contrast to the increase in carotenoids, no changes in the level of chlorophylls $a$ and $b$ were observed in $U$. compressa exposed to copper stress. On the other hand, the increase in photosynthesis may increase NADPH levels which may enhance the activities of enzymes belonging 


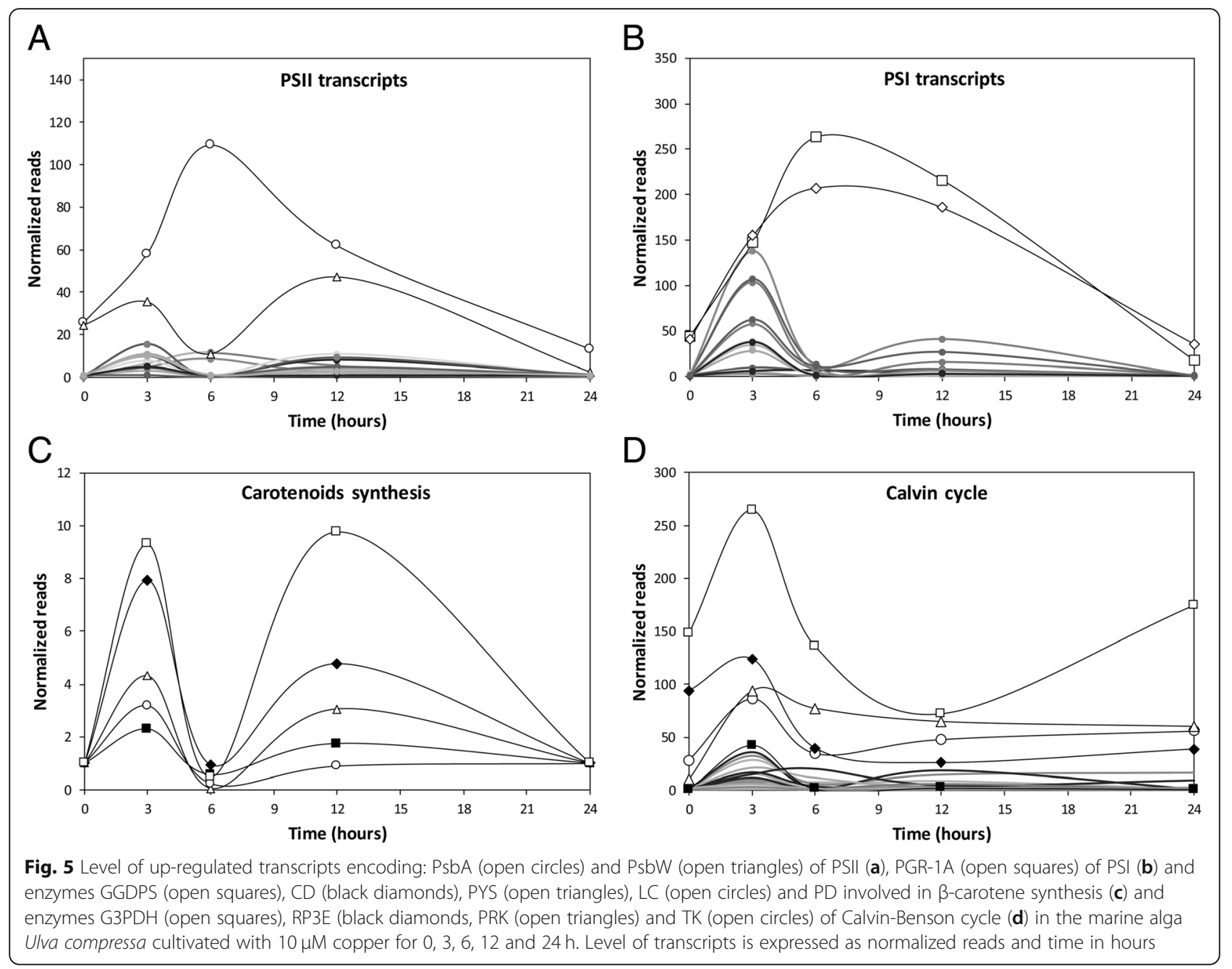

to the Calvin cycle leading to an increase in $\mathrm{C}$ assimilation. In addition, it was observed that at least $21 \%$ of transcripts are involved in secondary metabolism suggesting that the increase in $\mathrm{C}$ assimilation may be channeled to the synthesis of secondary metabolites such as phenolic compounds and terpenes. In addition, it is possible that $\mathrm{N}$ assimilation may also be increased in the alga cultivated with copper since $\mathrm{N}$ is required to repair damaged proteins or compounds that contain $\mathrm{N}$, but this assumption will be analyzed in the future.

Another interesting aspect deduced from the transcriptomic analyses is that almost $30 \%$ of the transcripts encode proteins having similarity to animal proteins corresponding to 11 model species that includes human, mouse and rat. In this sense, it has been shown in previous works that lipoxygenase in $U$. compressa uses arachidonic acid as substrate, as in animals, instead of linolenic or linoleic acids, as in plants [9]. In addition, $U$. compressa possess functional Transient Receptor Potential (TRP) channels that are normally present in vertebrate and invertebrates, but not in plants [16-18]. Moreover, $U$. compressa exhibits functional Voltage-Dependent Calcium Channels (VDCCs) that allow extracellular calcium entry leading to intracellular calcium release, as animal cells [19]. Furthermore, the release of calcium from endoplasmic reticulum (ER) occurs via NAADP-, $\mathrm{IP}_{3^{-}}$and ryanodine-dependent channels in $U$. compressa exposed to copper excess [20] and NAADP- and ryanodinedependent channels are not present in plants. In this sense, we have previously postulated that the marine macroalga $U$. compressa may contain an ancestral pool of genes and that part of these genes were lost in the animal lineage and another part was lost in photosynthetic organisms during evolution [16-18].

It is important to mention that only few transcriptomic or microarray analyses have been performed in marine macroalgae in response to copper stress and none of them reported a clear increase in the expression of genes encoding proteins involved in photosynthesis. In this sense, the brown macroalga $E$. siliciulosus cultivated with $1.8 \mu \mathrm{M}$ copper showed an increase in photosynthesis efficiency but only the level of a transcript 


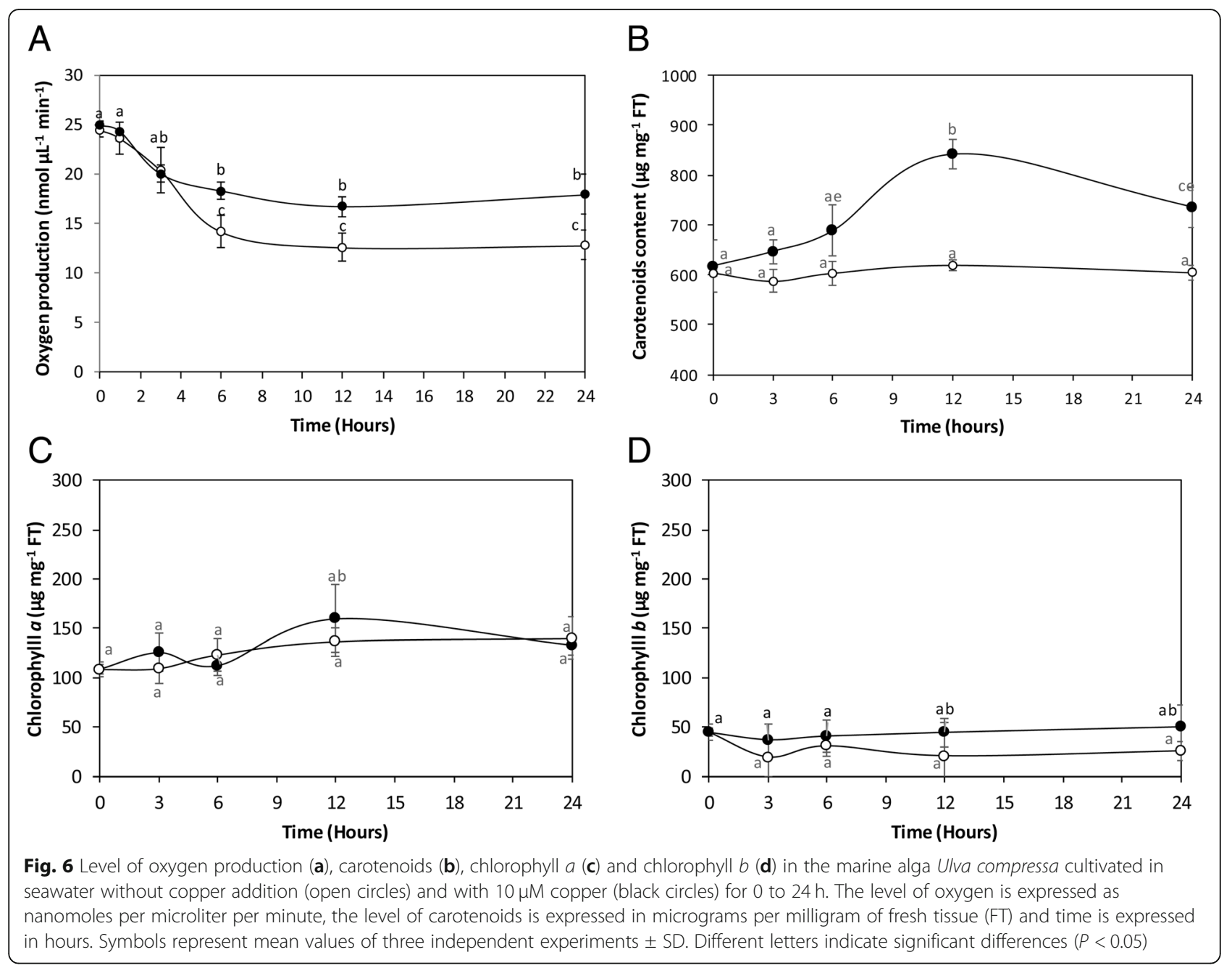

encoding L1818 (Lhc4-like protein) appeared to be enhanced [10]. In contrast, E. siliculosus showed an increase in transcripts of genes encoding enzymes of the oxylipin signaling pathway, a decrease in transcripts of the inositol signaling pathway and a modulation in the level of transcripts encoding some transcription factors in response to copper stress [10]. In addition, E. siliculosus exposed to copper displayed an increase in the level of transcripts encoding $\mathrm{ABC}$ transporters orthologs, P-type ATPases, ROS-detoxifying enzymes and a vanadium-dependent bromoperoxidase [10]. On the other hand, the green macroalga $U$. linza exposed to low and high temperature, high light, salt and UV-B, but not to copper stress, showed an increase in expression of photoprotective proteins LhcbSR and PsbS and an increase in expression a carbonic anhydrase, that improves carbon fixation. Moreover. $U$. linza exposed to abiotic stresses displayed an increase in the level of transcripts encoding glutamate dehydrogenases, that improves $\mathrm{N}$ fixation, and in the level of transcripts coding for antioxidant enzymes, that inhibits oxidative stress [15]. Thus, this is the first case of a marine macroalga showing a clear increase expression of $\mathrm{LCH}$ and PS subunits as well as in expression of enzymes involved in $\mathrm{C}$ assimilation and carotenoid synthesis in response to copper stress.

\section{Conclusions}

Here, we showed that the marine alga $U$. compressa exposed to copper stress exhibits a short-term gene expression response by enhancing the transcription of genes encoding proteins involved in assembly, repair and protection of PSII and PSI, and enzymes involved in carotenoid synthesis which is reflected in an increase in photosynthesis and carotenoid level. In addition, transcripts encoding enzymes from the Calvin-Benson cycle were also increased which may reflect an enhanced $\mathrm{C}$ assimilation.

\section{Methods}

\section{Alga and seawater sampling}

$U$. compressa was collected in Cachagua, a site with no history of metal pollution in central Chile ( $\left.32^{\circ} 34^{\prime} \mathrm{S}\right)$, 
transported to the laboratory in plastic bags at $4{ }^{\circ} \mathrm{C}$ inside a cooler. Algae were rinsed three times with filtered seawater obtained in Quintay ( $\left.33^{\circ} 12^{\prime} \mathrm{S}\right)$, a pristine site, cleaned manually and sonicated for $3 \mathrm{~min}$ in an ultrasound bath (Branson 3200, Danbury, CT, USA) in order to aid removing epiphytic bacteria and organic debris.

\section{In vitro cultures}

$U$. compressa (100 mg of fresh tissue) was cultivated in seawater with no nutrients addition without copper (control, $0 \mathrm{~h}$ ) or with $10 \mu \mathrm{M}$ of $\mathrm{CuCl}_{2}$ for $3,6,12$ and $24 \mathrm{~h}$ under an irradiance of $50 \mu$ moles $\mathrm{m}^{-2} \mathrm{~s}^{-1}$ on a photoperiod of $14 \mathrm{~h}$ light: $10 \mathrm{~h}$ dark, at $14{ }^{\circ} \mathrm{C}$. All samples were performed in duplicate except 0 and $24 \mathrm{~h}$ that were unique sample. All samples were washed with 2 $\mathrm{mL}$ of $100 \mathrm{mM}$ Tris-10 mM EDTA pH 7.0, twice for 10 min, in order to eliminate copper ions bound to the cell wall. Samples were dried with paper, frozen in liquid nitrogen and stored at $-80^{\circ} \mathrm{C}$.

RNA extraction, preparation of cDNA libraries, and sequencing Total RNA at 0, 3, 6, 12 and 24 h samples was isolated using EZNA total RNA Kit I (Omega Biotek, GA, USA). $U$. compressa (100 mg of each sample) was frozen in liquid nitrogen and homogenized in $1 \mathrm{~mL}$ of TRK buffer with $20 \mathrm{uL} 2$-mercaptoethanol. The samples were centrifuged, the supernatant recovered, mixed with ethanol $70 \%$ and transfered to HiBind RNA mini column and washed with RNA Wash Buffer I and II. Finally, total RNA was eluted with $50 \mu \mathrm{L}$ DEPC water. RNA samples were cleaned with GeneJet RNA Cleanup and Concentration Micro Kit (Thermo, MS, USA). Total RNA integrity was evaluated using a Fragment Analyzer and the software PROsize (Advanced Analytical, Iowa, USA). RNA samples were sended to BGI genomic center (Shenzhen, China), paired end cDNA libraries were prepared and sequenced using a Hi-Seq Illumina 4000.

\section{De novo assembly and annotation}

Reads obtained by RNA-seq were trimmed using Prinseq (version $0.20 .4 ; \quad-$ min_len 50 -min_qual_mean 20 -ns_max_n 1 -derep 14 -derep_min 9 -lc_method dust -lc_threshold 49 -trim_left 10 -trim_qual_right) and the quality controlled reads were visualized in Fastqc [21]. De novo transcriptomes were assembled using all the samples in Trinity (--min_contig_length 200) [22]. Sequences were blasted using BlastX software and UniprotKB/Swiss-Prot database, filtering hits with an e-value cutoff of $1 \mathrm{e}^{-3}$. Annotated sequences were classified according to their Gene Ontology using Blast2GO software [23] and those having an e-value of $1 \mathrm{e}^{-6}$ were selected. Sequences were classified according to GO domain (biological process, molecular function and cellular component) using Blast2GO online search.

\section{Detection of differentially expressed transcripts}

Quality controlled reads were mapped against the de novo transcriptome using Bowtie2 (version 2.2.9; default settings). Raw reads were counted using eXpress (version 1.5.1; default settings) and were then normalized to CPM units using Trinity's script abundance_estimates_to_matrix.pl under default settings [24]. Differentially expressed transcripts were identified as implemented in EdgeR (3.20.2) at an FDR $<0.01$ and Log2 Fold Change $>2$, with Trinity's script run_DE_analysis_from_samples_file.pl [25]. Differentially expressed transcripts were obtained by contrasting sample time points: 0 vs. 3 ; 0 vs. 6 ; 0 vs. $12 ; 0$ vs. 24 h. Differentially expressed transcripts were visualized as a heatmap by estimating Spearman's correlation coefficient on transcripts and samples, and hierarchical clustering (average).

\section{Kinetics of transcripts encoding proteins of photosystems, and enzymes of carotenoid synthesis and Calvin-Benson cycle}

Transcripts encoding proteins of photosystems, and enzymes of carotenoid synthesis and Calvin-Benson cycle were selected based on the annotation and GO domain (biological process). Reads of selected transcripts were normalized using Trimmed Mean of M-value (TMM) normalization method [26] they were analyzed by Multiple Experiment Viewer (MeV 4.8.1 version) software [27], groups of transcripts showing similar temporal expression pattern were created and overexpressed transcripts were selected from these groups.

\section{Detection of photosynthesis}

$U$. compressa ( $25 \mathrm{mg}$ of fresh tissue) was incubated in 2 $\mathrm{mL}$ of filtered seawater in the oxygraph chamber (Hansatech, model Oxygraph Plus, Norfolk, UK) and $\mathrm{O}_{2}$ production was measured for $10 \mathrm{~min}$ using a light intensity of 425 moles $\mathrm{m}^{-2} \mathrm{~s}^{-1}$.

\section{Quantification of carotenoids}

The level of carotenoids was determined as described in [28] with modifications. $U$. compressa tissue (100 $\mathrm{mg}$ ) was frozen in liquid nitrogen and homogenized in a mortar using a pestle. Ten $\mathrm{mL}$ of acetone $(80 \%)$ were added, the mixture was shaken using a vortex for $10 \mathrm{~s}$ and incubated $15 \mathrm{~min}$ in ice. The mixture was centrifuged at $3000 \mathrm{rpm} \times 10 \mathrm{~min}$ at $4{ }^{\circ} \mathrm{C}$ and the supernatant was recovered. The absorbance was determined at 480 and $510 \mathrm{~nm}$ in a spectrophotometer (Agilent, model Cary 8454, CA, USA) and the level of carotenoids was determined using the formula: 


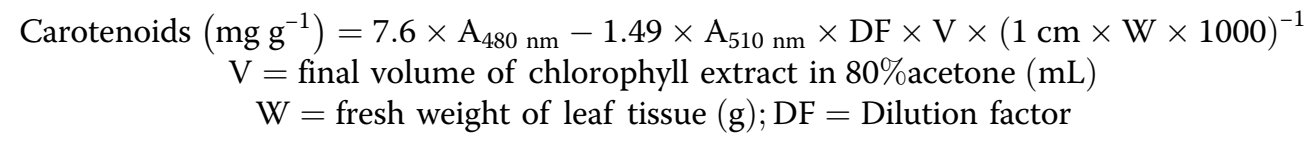

\section{Quantification of chlorophylls}

The level of chlorophylls was determined as described in [29]. U. compressa (100 mg of FT) was frozen in liquid nitrogen and homogenized with $2 \mathrm{~mL} 80 \%$ acetone. The mixture was centrifuged at $3000 \mathrm{rpm}$ for $10 \mathrm{~min}$ at $4{ }^{\circ} \mathrm{C}$, the supernatant was recovered and diluted 10 times with $80 \%$ acetone. The absorbance was determined at 649 and $663 \mathrm{~nm}$. The level of chlorophylls $a$ and $b$ was calculated according to the formula:

$$
\begin{aligned}
& \text { Chlorophyll } a\left(\mu \mathrm{g} \mathrm{mL}^{-1}\right)=12.7 \times \mathrm{A}_{663 \mathrm{~nm}}-2.69 \times \mathrm{A}_{645 \mathrm{~nm}} \\
& \text { Chlorophyll } b\left(\mu \mathrm{g} \mathrm{mL}^{-1}\right)=22.9 \times \mathrm{A}_{645 \mathrm{~nm}}-4.68 \times \mathrm{A}_{663 \mathrm{~nm}}
\end{aligned}
$$

\section{Statistical analyses}

Significant differences in oxygen production and carotenoid levels were calculated with one-way ANOVA at 95\% confidence interval, followed by a Tukey's multiple comparison post-test using the statistical software Prism 6 (GraphPad Software Inc., California, USA). Analyses were conducted as three independent replicates.

\section{Additional files}

Additional file 1: Figure S1. Preprocessing of reads and transcriptome length distribution. (a) Percentage of preprocessed reads starting from total sequenced reads ( $\mathrm{X}$ axis) per library ( $\mathrm{Y}$ axis). "Filtered" shows the percentage of reads filtered out by the quality control (QC) process. "Bacteria" shows the percentage of bacterial reads (mapped against RefSeq's bacteria database). "U. compressa" shows quality-controlled and decontaminated reads, which we used for downstream analysis. (b) Histogram showing the length distribution (bp; $X$ axis) of the assembled transcripts (contigs; $Y$ axis) of the Ulva compressa transcriptome. We assembled a total of 106,704 transcripts with an average length of 868 bp. (TIF 917 kb)

Additional file 2: Figure S2. Pie chart of the percentage of protein sequences associated with different molecular functions (a) and cellular component (b) obtained from the transcriptomic analyses performed in the marine alga $U$. compressa cultivated with $10 \mu \mathrm{M}$ of copper for $0,3,6$, 12 and $24 \mathrm{~h}$. (TIF $2198 \mathrm{~kb}$ )

\section{Abbreviations}

CD: Carotene desaturase; DT: Dry tissue; ER: Endoplasmic reticulum; FBP: Fructose 1,6 biphosphatase; FT: Fresh tissue; G3PDH: Glyceraldehyde 3 phosphate dehydrogenase; GGDS: Geranylgeranyl diphosphate synthase; LC: Lycopene $\beta$ - cyclase; LHCl: Light harvesting complex I; LHCII: Light harvesting complex II; PD: Phytoene desaturase; PGK: Phosphoglycerate kinase; PHS: Phytoene synthase; PSI: Photosystem I; PSII: Photosystem II; R5PI: Ribose 5-phophate isomerase; RbcS: Small subunit of ribulose 1,5 biphosphate carboxylase/oxygenase (rubisco); ROS: Reactive oxygen species; RP3E: Ribulose phosphate 3; SHBP: Seudoheptulose 1,7 biphosphatase phosphoribulokinase; TK: Transketolase

\begin{abstract}
Acknowledgments
We are grateful to all the members of A. Moenne and E. Castro-Nallar teams that performed the transcriptomic analyses and the interpretation of results. ECN was funded by "CONICYT-FONDECYT Iniciación 11160905". ECN would like to thank The George Washington University's high-performance computing facility, ColonialOne, for providing data storage, support, and computing power for genomic analyses (colonialone.gwu.edu).
\end{abstract}

\section{Funding}

This work was financed by Fondecyt 1160013 to A.M., postdoctoral fellowship Dicyt-USACH to F.R. and postdoctoral project Fondecyt 3170511 to D.L.

\section{Availability of data and materials}

https://www.ncbi.nlm.nih.gov/sra/SRP145672 (SRA records will be accessible with the following link after the indicated release date May 12, 2019). https://figshare.com/articles/Rodriguez_et_al_2018/6267284

\section{Authors' contributions}

F.R. performed in vitro cultures and extraction of total RNA, C.M. determined integrity of RNA; K.N.M. performed quality control of raw reads, assembled the de novo transcriptome; annotated predicted transcripts, and performed the differential transcript analysis; F.R. annotated and classified transcripts in GO categories; D.L. selected up-regulated transcripts and performed statistical analyses; E.C.N. proposed and supervised all the bioinformatics analyses, interpreted results, and reviewed the manuscript; A.G. carried out photosynthesis experiments and prepared figures; F.R and D.L. determined carotenoid and chlorophyll levels; J.P.H.T. and F.R. participated in results discussion; A. M. wrote the paper, and A.M, F.R. and DL. interpreted results, A.M., J.P.H.T. and D.L. financed the experimental work. All authors read and approved the final manuscript.

Ethics approval and consent to participate

Not applicable.

\section{Consent for publication}

All the authors approve to publish this manuscript.

\section{Competing interests}

The authors declare that they have no competing interests.

\section{Publisher's Note}

Springer Nature remains neutral with regard to jurisdictional claims in published maps and institutional affiliations.

\section{Author details \\ ${ }^{1}$ Faculty of Chemistry and Biology, University of Santiago of Chile, Av. Libertador Bernardo O'Higgins, 3363 Santiago, Chile. ${ }^{2}$ Center for Bioinformatics and Integrative Biology, Facultad de Ciencias de la Vida, Universidad Andrés Bello, Santiago, Chile. ${ }^{3}$ Center of Plant Biotechnology, Facultad de Ciencias de la Vida, Universidad Andrés Bello, Santiago, Chile. ${ }^{4}$ FONDAP Center for Genome Regulation, Universidad Andrés Bello, Santiago, Chile. ${ }^{5}$ Center for the Development of Nanoscience and Nanotechnology (CEDENNA), Santiago, Chile.}

Received: 16 August 2018 Accepted: 6 November 2018 Published online: 20 November 2018

\section{References}

1. Bothe H. Plants in heavy metal soils. In: Sherameti I, Varma A, editors. Detoxification of heavy metals. Berlin: Springer; 2011. p. 35-57.

2. Singh $S$, Parihar $P$, Singh $R$, Singh VP, Prasad $S M$. Heavy metal tolerance in plants: role of transcriptomics, proteomics, metabolomics, and lonomics. Front Plant Sci. 2016;6:1143. 
3. Küpper $H$, Küpper F, Spiller M. Environmental relevance of heavy metalsubstituted chlorophylls using the example of water plants. J Exp Bot. 1996; 47:259-66.

4. Küpper H, Šetlík I, Spiller M, Küpper FC, Prášil O. Heavy metal-induced inhibition of photosynthesis: targets of in vivo heavy metal chlorophyll formation. J Phycol. 2002;38:429-41.

5. Rocchetta I, Küpper H. Chromium- and copper-induced inhibition of photosynthesis in Euglena gracilis analysed on the single-cell level by fluorescence kinetic microscopy. New Phytol. 2009;182:405-20.

6. Lidon FC, Ramalho JC, Henriques FS. Copper inhibition of rice photosynthesis. J Plant Physiol. 1993;142:12-7.

7. Cook CM, Kostidou A, Vardaka E, Lanaras T. Effects of copper on the growth, photosynthesis and nutrient concentrations of Phaseolus plants. Photosynthetica. 1997;34:179-93.

8. Ratkevicius N, Correa JA, Moenne A. Copper accumulation, synthesis of ascorbate, and activation of ascorbate peroxidase in Enteromorpha compressa (L.) Grev. (Chlorophyta) from heavy etal-enriched environments in northern Chile. Plant Cell Environ. 2003;26:1599-608.

9. González A, Vera J, Castro J, Dennett G, Mellado M, Morales B, et al. Cooccurring increases of calcium and organellar reactive oxygen species determine differential activation of antioxidant and defense enzymes in Ulva compressa (Chlorophyta) exposed to copper excess. Plant Cell Environ. 2010;33:1627-40

10. Ritter A, Dittami SM, Goulitquer S, Correa JA, Boyen C, Potin P, et al. Transcriptomic and metabolomic analysis of copper stress acclimation in Ectocarpus siliculosus highlights signaling and tolerance mechanisms in brown algae. BMC Plant Biol. 2014;14:116.

11. Tonon-Pedroso A, Zaini PA, dos Reis Falcão V, Oliveira MC, Collén J, Boyen C, et al. Gracilaria tenuistipitata (Rhodophyta) tolerance to cadmium and copper exposure observed through gene expression and photosynthesis analyses. J Appl Phycol. 2018;30:1-13.

12. Li YX, Zhou S, Zhao FJ, Liu Y, Fan PP, Wang GC. Physiological responses of Porphyra haitanesis to different copper and zinc concentrations. Braz J Oceanogr. 2010;58:261-7.

13. Andrade LR, Farina M, Amado Filho GM. Effects of copper on Enteromorpha flexuosa (Chlorophyta) in vitro. Ecotoxicol Environ Saf. 2004;58:117-25.

14. Zhang X, Ye N, Liang C, Mou S, Fan X, Xu J, et al. De novo sequencing and analysis of the Ulva linza transcriptome to discover putative mechanisms associated with its successful colonization of coastal ecosystems. BMC Genomics. 2012;13:565.

15. Laporte D, Valdés N, González A, Sáez CA, Zúñiga A, Navarrete A, et al. Copper-induced overexpression of genes encoding antioxidant system enzymes and metallothioneins involve the activation of CaMs, CDPKs and MEK1/2 in the marine alga Ulva compressa. Aquat Toxicol. 2016;177:433-40.

16. Gómez M, González A, Saez CA, Morales B, Moenne A. Copper-induced activation of TRP channels promotes extracellular calcium entry, activation of CaMs and CDPKs, copper entry and membrane depolarization in U/va compressa. Front Plant Sci. 2015;6:182

17. Gómez M, González A, Sáez CA, Moenne A. Copper-induced membrane depolarizations involve the induction of mosaic TRP channels, which activate VDCC leading to calcium increases in Ulva compressa. Front Plant Sci. 2016;7:754

18. Gómez M, González A, Moenne F, Sáez CA, Moenne A. Copper-induced early responses involve the activation of transient receptor potential (TRP) channels, release of amino acids, serotonin and adrenalin, and activation of homologs of glutamate, adrenalin and serotonin receptors in the marine alga Ulva compressa. Algal Res. 2017;26:115-22.

19. González A. Cabrera M de los A, Mellado M, Cabello S, Márquez S, Morales $B$, et al. Copper-induced intracellular calcium release requires extracellular calcium entry and activation of L-type voltage-dependent calcium channels in Ulva compressa. Plant Signal Behav. 2012;7:728-32.

20. González A, Cabrera MA, Henríquez MJ, Contreras RA, Morales B, Moenne A. Cross talk among calcium, hydrogen peroxide, and nitric oxide and activation of gene expression involving calmodulins and calciumdependent protein kinases in Ulva compressa exposed to copper excess. Plant Physiol. 2012;158:1451-62.

21. Schmieder R, Edwards R. Quality control and preprocessing of metagenomic datasets. Bioinformatics. 2011;27:863-4.

22. Grabherr MG, Haas BJ, Yassour M, Levin JZ, Thompson DA, Amit I, et al. Fulllength transcriptome assembly from RNA-Seq data without a reference genome. Nature Biotechnol. 2011;29:644-52.
23. Conesa A, Götz S, García-Gómez JM, Terol J, Talón M, Robles M. Blast2GO: a universal tool for annotation, visualization and analysis in functional genomics research. Bioinformatics. 2005;21:3674-6.

24. Trapnell C, Williams BA, Pertea G, Mortazavi AM, Kwan G, van Baren MJ, Salzberg SL, Wold B, Pachter L. Transcript assembly and quantification by RNA-Seq reveals unannotated transcripts and isoform switching during cell differentiation. Nat Biotechnol. 2010;28:510-5.

25. Robinson MD, McCarthy DJ, Smyth GK. edgeR: a Bioconductor package for differential expression analysis of digital gene expression data. Bioinformatics. 2010;26:139-40.

26. Robinson MD, Oshlack A. A scaling normalization method for differential expression analysis of RNA-seq data. Genome Biol. 2010;11:R25.

27. Howe E, Holton K, Nair S, Schlauch D, Sinha R, Quackenbush J. MeV: MultiExperiment viewer. In: Ochs MF, Casagrande JT, Davuluri RV, editors. Biomedical informatics for Cancer research. Berlin: Springer. p. 267-77.

28. Stramarkou M, Papadaki S, Kyriakopoulou K, Krokida M. Recovery of functional pigments from four different species of microalgae. IOSR J Environ Sci, Toxicol Food Technol. 2016;10:26-30.

29. Arnon DI. Copper enzymes in isolated chloroplasts, polyphenol oxidase in Beta vulgaris. Plant Physiol. 1949;24:1-15.
Ready to submit your research? Choose BMC and benefit from:

- fast, convenient online submission

- thorough peer review by experienced researchers in your field

- rapid publication on acceptance

- support for research data, including large and complex data types

- gold Open Access which fosters wider collaboration and increased citations

- maximum visibility for your research: over $100 \mathrm{M}$ website views per year

At BMC, research is always in progress.

Learn more biomedcentral.com/submissions 